\title{
L Tipi Bir Kirişin Sayısal ve Deneysel Modal Analizi
}

\author{
${ }^{1}$ Recep Yılmaz, ${ }^{2 *}$ Safa Eldek, ${ }^{3}$ Erdi Gülbahçe \\ ${ }^{1}$ Tübitak UME, Ulusal Metroloji Enstitüsü, Gebze-Kocaeli, Türkiye \\ ${ }^{* 2}$ Mesa Makina Döküm Gıda San. ve Tic. A.Ş., Konya, Türkiye \\ ${ }^{3}$ Mekatronik Mühendisliği Bölümü, KTO Karatay Üniversitesi, Konya, Türkiye
}

\section{Özet}

Titreşim, makinelerde bağlantı parçalarına, ana yapılara ve eyleyici sistemlere büyük hasarlar verebilmektedir. Ayrıca mekanik titreşim ses ve gürültülere sebep olarak insan sağlı̆̆ını ve konforunu olumsuz yönde etkileyebilmektedir. Bu sebeple titreşim, dinamik olarak çalışan sistemlerde istenmeyen bir durum olmakla beraber, titreşim ölçümleri ve analizleri mühendislik alanında önemli bir çalışma konusu olmuştur. Bu çalışmada L tipi bir kirişin sonlu elemanlar yöntemi kullanan sayısal analiz programlarından Solidworks Simulation ve Ansys programları ile modal analizleri gerçekleştirilmiştir. Ayrıca tasarlanan test düzeneğine iki adet gerinim ölçer uygulanarak serbest sönümlü titreşim analizi ile deneysel veriler elde edilmiştir. Hem sayısal hem de deneysel modal analizlerden elde edilen sonuçlar karşılaştırılmıştır.

Anahtar Kelimeler: Modal analiz, Sonlu elemanlar yöntemi, Doğal frekans, Titreşim

\begin{abstract}
Vibration can cause extensive damage to connecting parts, main structures and individual systems in machines. In addition, mechanical vibration adversely affects human health and comfort by causing sound and noise. Therefore, vibration is an undesirable condition in dynamically functioning systems, but vibration measurements and analysis have been an important study in the field of engineering. In this study, modal analyses were carried out with Solidworks Simulation and Ansys programs, one of the numerical analysis programs that use the method of finite elements of an L-type beam. In addition, two strain gauges were applied to the designed test assembly and experimental data were obtained by free damp vibration analysis. Results from both numerical and experimental modal analyses were compared.
\end{abstract}

Keywords: Modal analyses, Finite element method, Natural frequency, Vibration

*Sorumlu Yazar: Safa Eldek Adres: Organize Sanayi Bölgesi İhsan Dede Caddesi 20 Nolu Sokak No:5, Konya, Türkiye. E-mail adres: safa.eldek@ mesamakina.com.tr, Telefon: +903322391872 


\section{Giriş}

Günümüz dünyasında rekabet koşulları, üretim kaynaklı veya süreçle ilgili meydana gelebilecek bir hataya yer vermemektedir. Üretilecek ürün ile ilgili bilgisayar ortamında gerçekleştirilen çeşitli sayısal analizlerin deneysel olarak doğrulanmasının müşteri firmalar tarafindan istenmesi ve bu isteklerin gün geçtikçe artması sonucu, bu alanda hizmet veren işletmeler tarafından araştırma ve geliştirme departmanları kurularak talep edilen ürün kalite düzeyine ulaşılması hedeflenmektedir. Yaşadığımız bu son asırda, sonlu elemanlar yöntemi gibi sayısal optimizasyon tekniklerinin ürün tasarımında kullanılmaya başlanılmasıyla beraber analitik olarak çözümü zor ve bazen imkânsız olan, yapıda meydana gelen gerilmeler ve yapının modal karakteristikleri iyi bir yakınsama ile kolaylıkla tespit edilebilmektedir. Defalarca deneme yanılma yoluna giderek kaybedilecek zaman ve maliyet yerine bilgisayar ortamında sonlu eleman metodu kullanan sayısal analiz programlarıyla tespit edilen kritik gerilme ve gerinim bölgeleri üzerine deneysel olarak gidilerek ciddi bir üretim tasarrufu sağlanabilmektedir $[1,2,3,4]$. Bunun yanı sıra çalışma koşullarından kaynaklanan titreşimlerin yol açacağı yıkımların önüne geçebilmek için yapının modal karakteristiğinin de iyi bilinmesi gerekmektedir. Yapının modal karakteristiği tasarımda önemli bir rol almaktadır. Bunun nedeni sistemin doğal frekansı ile çalışma koşullarından kaynaklanan titreşim frekansının çakışması durumunda sistemin rezonansa girebilme tehlikesidir. Titreşim bir denge noktası etrafında meydana gelen mekanik salınım hareketidir [5]. Titreşimler dinamik olarak çalışan sistemlerde istenmeyen bir durumdur. Titreşim, makinelerde bağlantı parçalarına, ana yapılara ve eyleyici sistemlere büyük hasarlar verebilmektedir. Ayrıca mekanik titreşimler ses ve gürültülere sebep olarak insan sağlığını ve konforunu olumsuz yönde etkilemektedirler. Bu yüzden titreşim ölçümleri ve analizleri mühendislik açısından önemli bir çalışma konusudur [6]. Sunulan bu çalışmada L tipi bir kirişin sayısal analiz programlarında sonlu elemanlar yöntemi ile modal analizleri gerçekleştirilmiş ve elde edilen sonuçlar deneysel veriler ile karşılaştırılmıştır.

\section{Analiz Modeli}

Tasarlanan L tipi kirişin genel görüntüsü ve ölçüleri Şekil 1'de gösterilmiştir. Analiz modeli sayısal analiz programlarında Şekil 1'de A harfi ile gösterilen bölgeden sabitlenmiştir. Deneysel analizde ise bu kısım ankastre olarak sabitlenmiştir. [7]
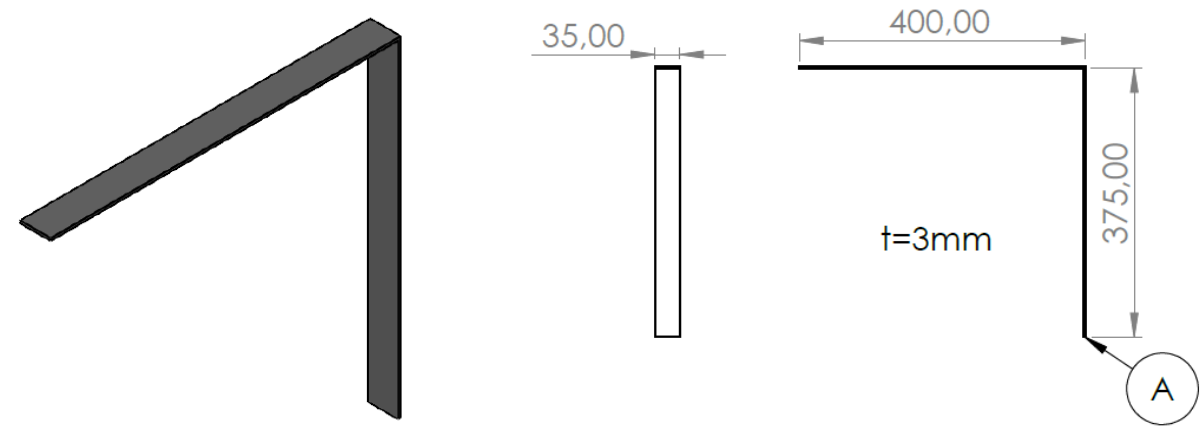

Şekil 1. L tipi kiriş genel görüntüsü ve ölçüleri 
Kiriş malzemesi olarak St-37 çeliği kullanılmıştır. St-37 çeliğinin fiziksel ve mekanik özellikleri Tablo 1'de verilmiştir.

Tablo 1. St-37 çeliği fiziksel ve mekanik özellikleri [8]

\begin{tabular}{|l|r|l|}
\hline Elastisite Modülü & $2.1 \mathrm{e} 5$ & $\mathrm{~N} / \mathrm{mm}^{2}$ \\
\hline Poisson Oranı & 0.28 & \\
\hline Gerilme Mukavemeti & 360 & $\mathrm{~N} / \mathrm{mm}^{2}$ \\
\hline Akma Mukavemeti & 235 & $\mathrm{~N} / \mathrm{mm}^{2}$ \\
\hline Termal Genişleme Katsayısı & $1.1 \mathrm{e}-5$ & $/ \mathrm{K}$ \\
\hline Kütle Yoğunluğu & 7800 & $\mathrm{~kg} / \mathrm{m}^{3}$ \\
\hline
\end{tabular}

\section{Sayısal Analizler}

\subsection{Solidworks ile Modal Analiz}

Tasarlanan L tipi kirişin modal analizi, sonlu elemanlar yöntemi kullanan sayısal analiz programlarından ilk olarak Solidworks Simulation programı ile gerçekleştirilmiştir. Şekil 2'de, tasarlanan L tipi kirişin sabitlenmiş ve mesh işlemi gerçekleştirilmiş hali gösterilmiştir. Analiz modeli Şekil 1'de verilen A bölgesinden sabitlenmiştir.
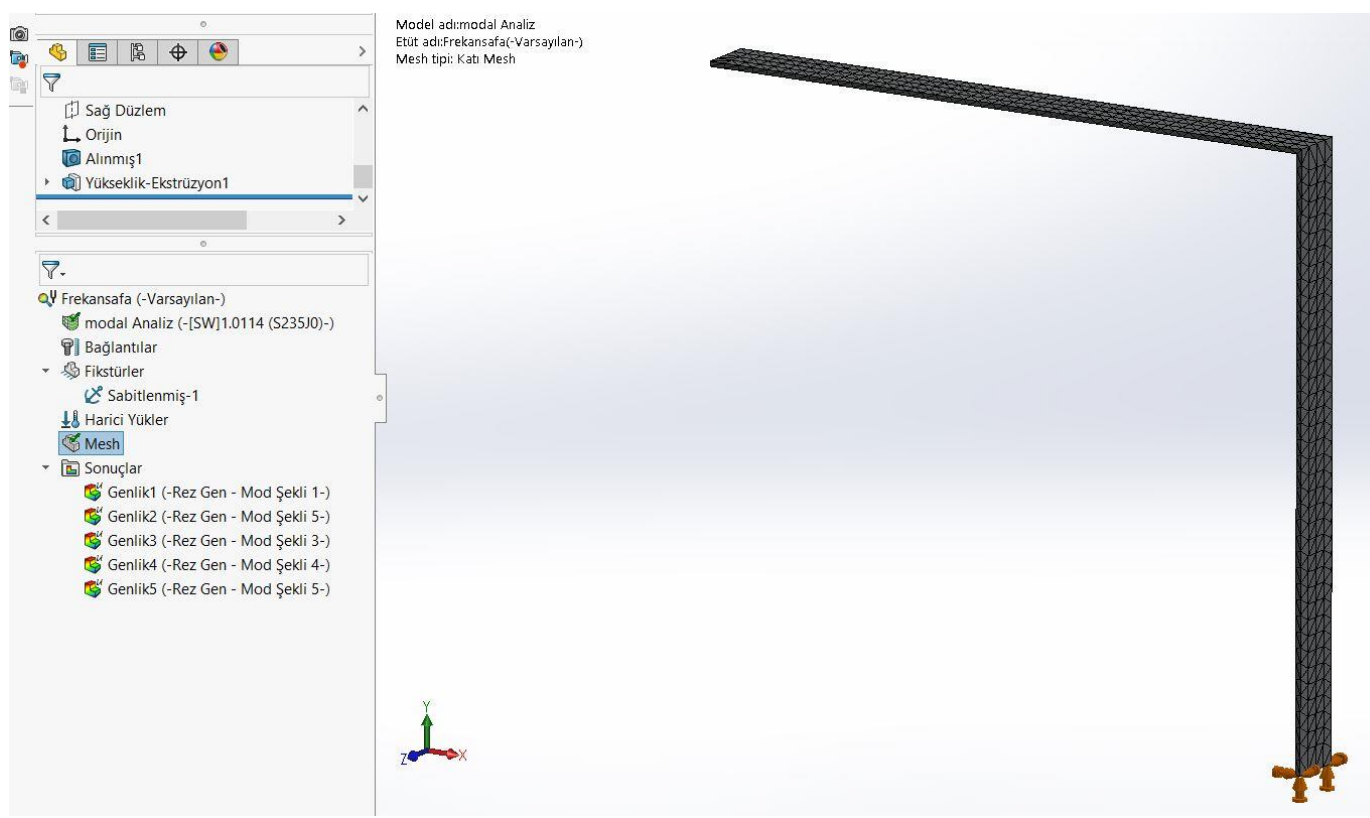

Şekil 2. Modelin Solidworks Simulation programı üzerindeki gösterimi

Sayısal modal analiz çalışmasının sonucunda beş adet mod değeri ve mod şekli elde edilmektedir. Fakat tasarımı doğrudan ilgilendiren kritik mod değeri birinci mod değeridir [1]. Analiz sonucunda elde edilen birinci mod değeri 5,67 Hz'dir. Şekil 3'de Solidworks Simulation programı kullanılarak sayısal modal analiz sonucunda elde edilen birinci kritik mod değeri ve mod şekli verilmiştir. 


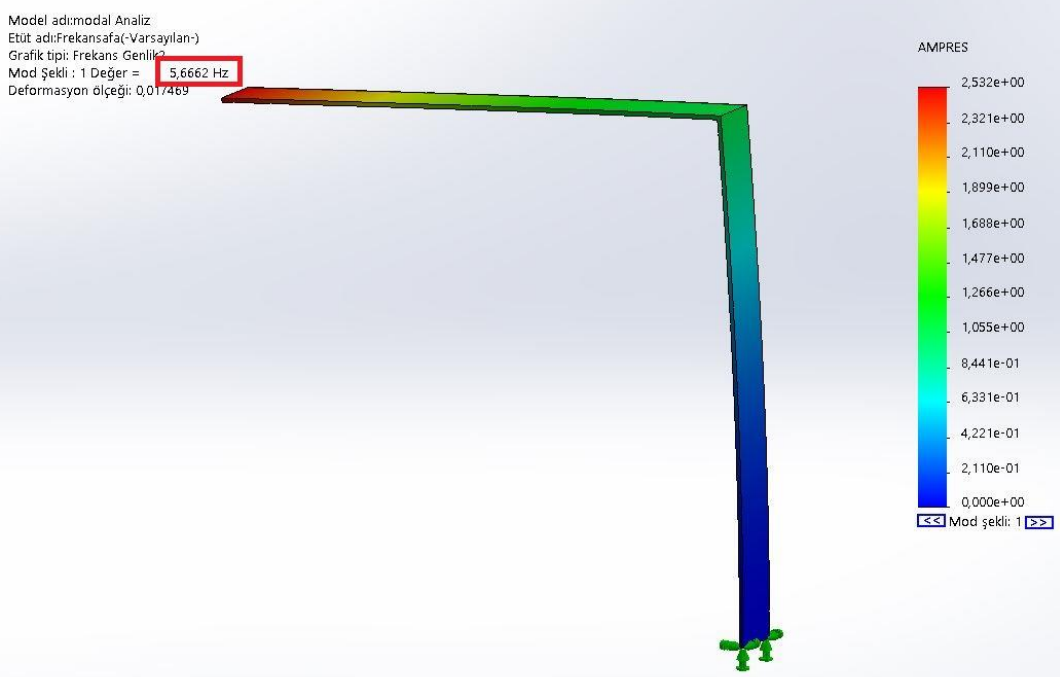

Şekil 3. Solidworks Simulation ile elde edilen birinci mod değeri ve şekli

Modal analiz sonucunda elde edilen tüm mod değerleri Tablo 2'de birlikte verilmiştir. Şekil 4'de ise son dört mod değerine ait mod şekilleri gösterilmiştir.

Tablo 2. L tipi kirişin mod değerleri

\begin{tabular}{|c|c|c|c|c|}
\hline 1.Mod Değeri & 2.Mod Değeri & 3.Mod Değeri & 4.Mod Değeri & 5.Mod Değeri \\
\hline $5,67 \mathrm{~Hz}$ & $10,13 \mathrm{~Hz}$ & $15,55 \mathrm{~Hz}$ & $74,24 \mathrm{~Hz}$ & $115,69 \mathrm{~Hz}$ \\
\hline
\end{tabular}

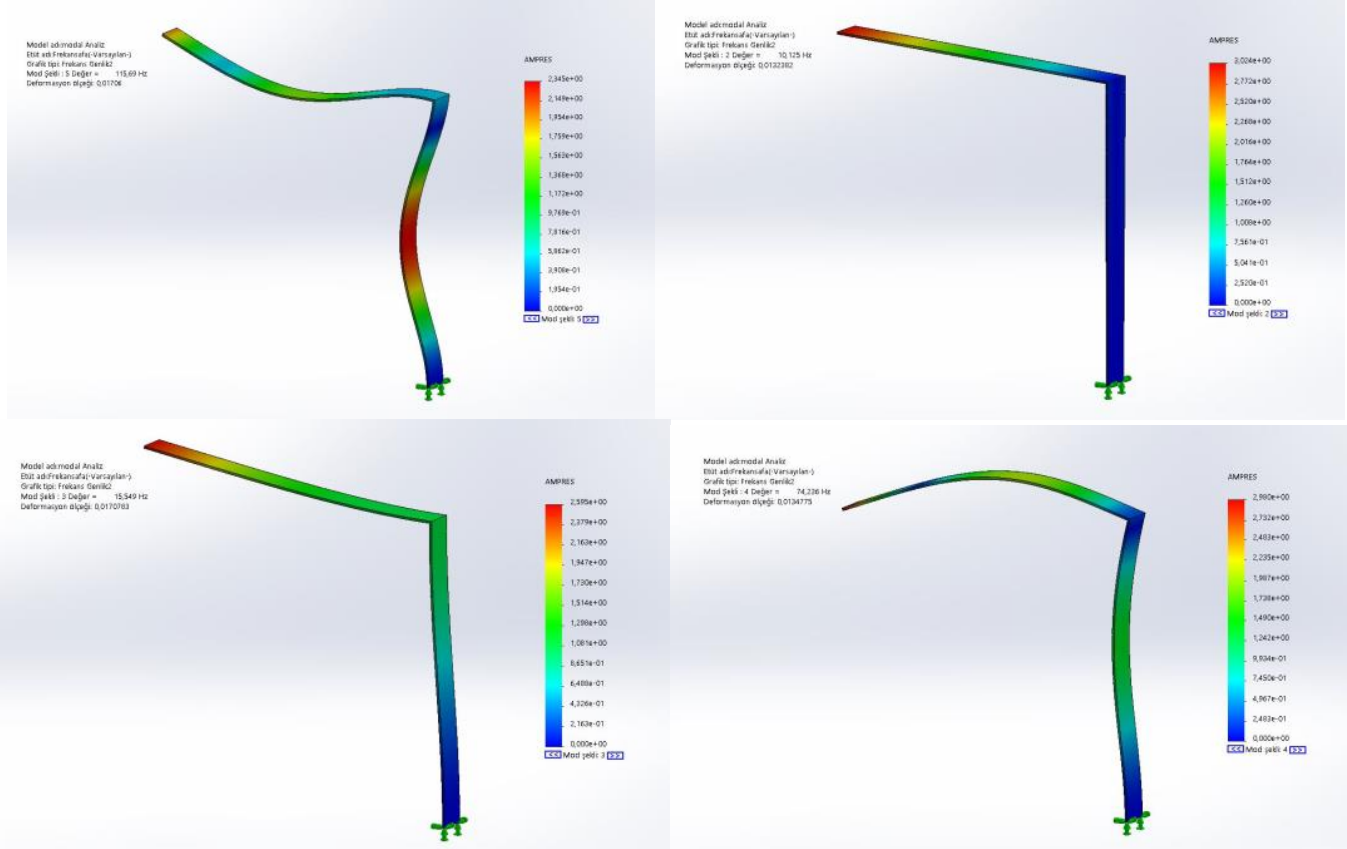

Şekil 4. Solidworks Simulation ile elde edilen son dört mod değeri ve mod şekilleri 


\subsection{Ansys ile Modal Analiz}

Tasarlanan L tipi kirişin modal analizi, sonlu elemanlar yöntemi kullanan sayısal analiz programlarından Ansys programı ile de ayrıca gerçekleştirilmiştir. Şekil 5'de, tasarlanan L tipi kirişin Ansys ortamındaki görüntüsü verilmiştir. Gerekli sınır koşulları tanımlanmıştır. Model yine Şekil 1'de gösterilen A bölgesinden sabitlenmiştir.

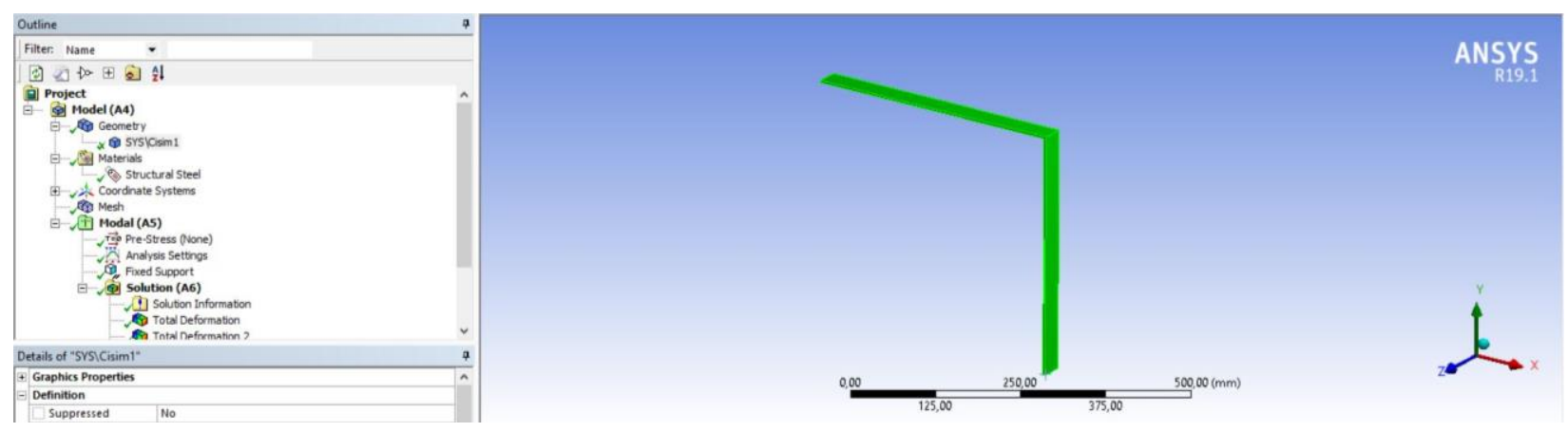

Şekil 5. Modelin Ansys programı üzerindeki gösterimi

Ansys programı ile gerçekleştirilen sayısal modal analiz sonucunda elde edilen birinci mod değeri 5,50 Hz'dir ve Şekil 6'da birinci mod değeri ve mod şekli gösterilmiştir.

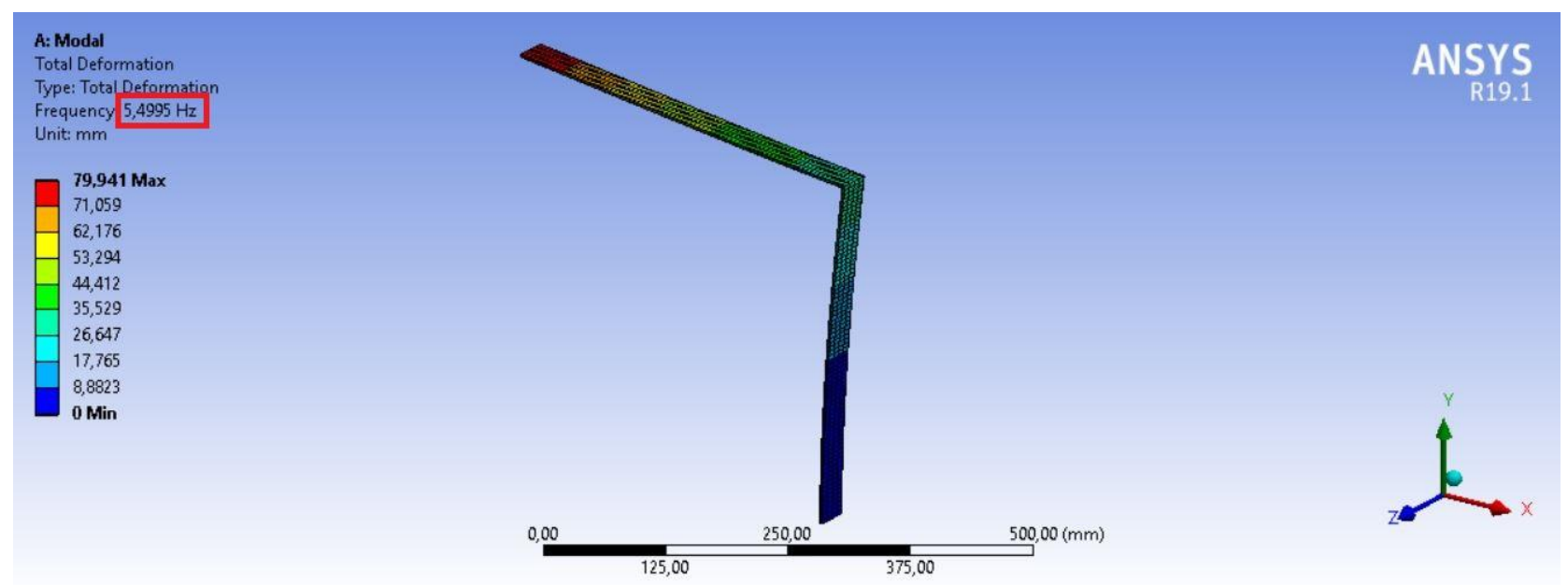

Şekil 6. Ansys ile elde edilen birinci mod değeri ve şekli

Ansys programı ile sayısal modal analiz sonucunda elde edilen tüm mod değerleri Tablo 3 'de birlikte verilmiştir.

Tablo 3. L tipi kirişin mod değerleri

\begin{tabular}{|c|c|c|c|c|}
\hline 1.Mod Değeri & 2.Mod Değeri & 3.Mod Değeri & 4.Mod Değeri & 5.Mod Değeri \\
\hline $5,50 \mathrm{~Hz}$ & $9,60 \mathrm{~Hz}$ & $15,00 \mathrm{~Hz}$ & $72,14 \mathrm{~Hz}$ & $111,40 \mathrm{~Hz}$ \\
\hline
\end{tabular}


Şekil 7'de ise son dört mod değerine ait mod şekilleri gösterilmiştir.

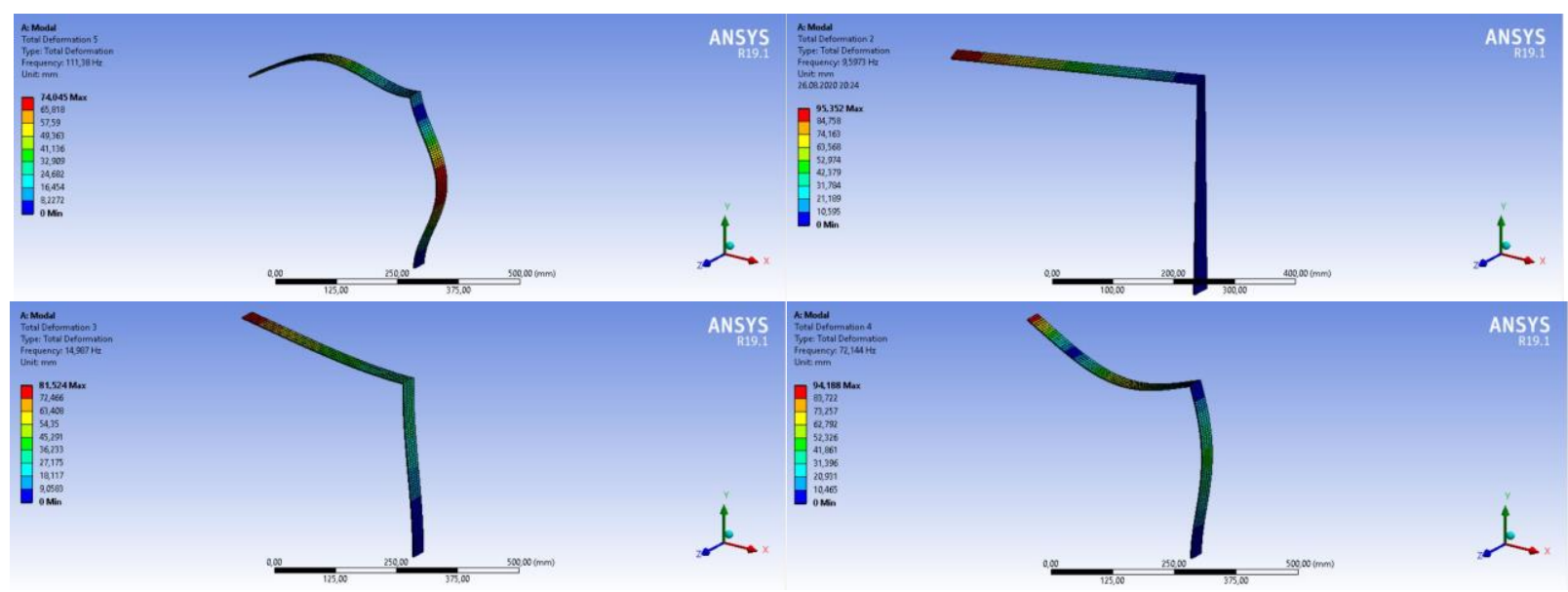

Şekil 7. Ansys ile elde edilen son dört mod değeri ve mod şekilleri

\subsection{Deneysel Modal Analiz}

Deneysel modal analizde bir ucu ankastre şekilde sabitlenmiş L tipi bir kirişin serbest sönümlü titreşim analizi gerçekleştirilmiştir. Deney düzeneğinde iki adet gerinim ölçer kullanılmıştır. Gerinim ölçerler test düzeneğine yarım köprü şeklinde uygulanmıştır. Serbest sönümlü titreşim hareketi boyunca gerinim ölçerlerin yapıştırıldığı alandaki gerinim değerleri veri toplama cihazı ile ölçülmüştür. Veri toplama cihazı ile gerinim ölçerden alınan veriler Matlab yazılımına aktarılmış ve yazılım ara yüzünde logaritmik azalma metodu kullanılarak kirişe ait sönüm periyodu, sönüm oranı ve birinci mod değeri gibi titreşim parametreleri deneysel olarak elde edilmiştir. [7] Şekil 8'de deneysel modal analiz düzeneği gösterilmiştir.

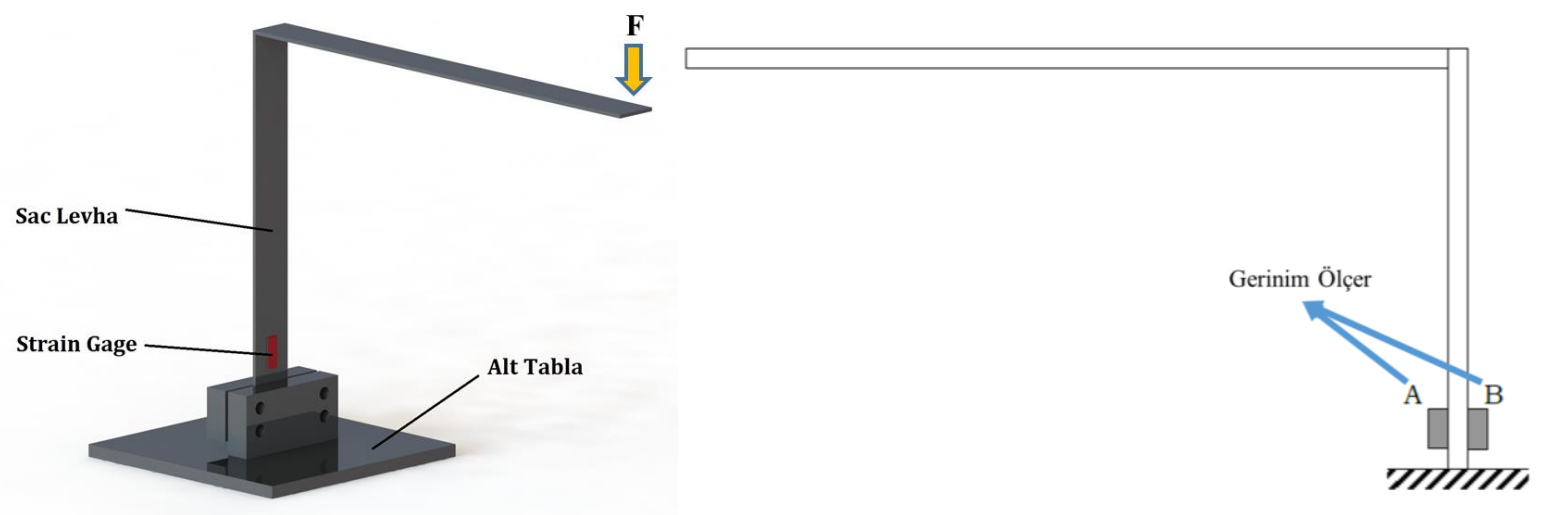

Şekil 8. Deneysel modal analiz düzeneği

Bu çalışma kapsamında gerçekleştirilen serbest sönümlü titreşim analizine ait sonuçların Matlab Command Window üzerinden alınan görüntüsü Şekil 9'da verilmiş̧ir. 


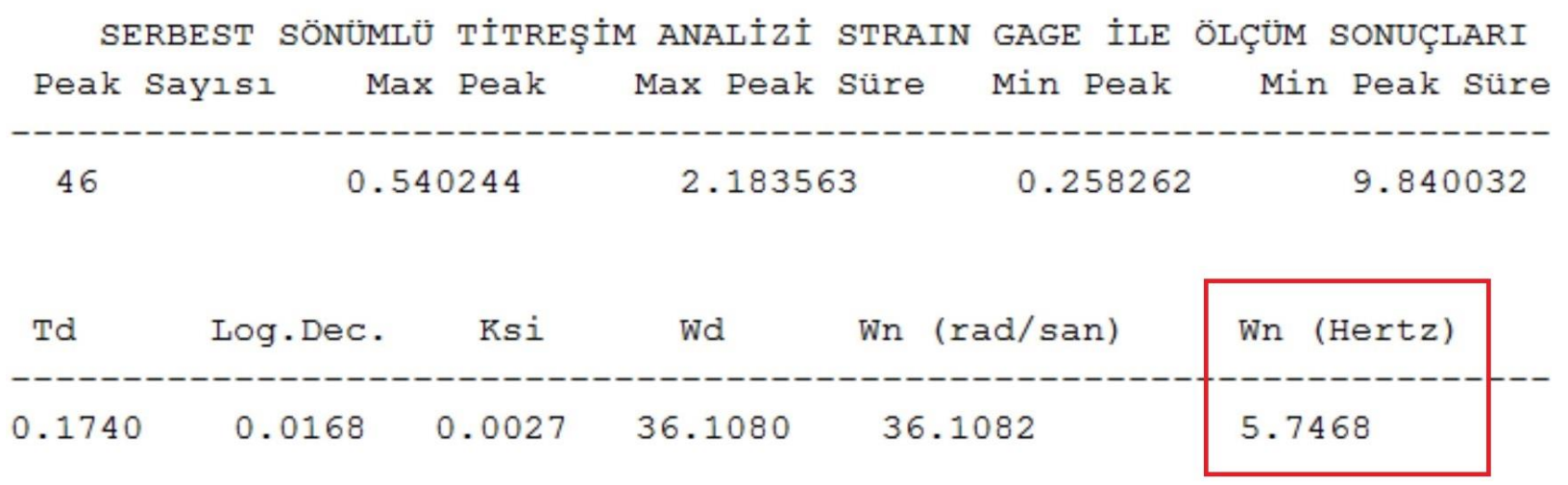

Şekil 9. Deneysel modal analiz sonuçları

\subsection{Sonuçların Karşılaş̧tırılması}

Bir L tipi kirişin modal analizi iki farklı sayısal analiz programında gerçekleştirilmiştir. Sayısal analiz sonuçlarının ilk mod değerleri ile deneysel olarak yapılan analizin sonuçları karşılaştırılmış ve Tablo 4'de verilmiştir.

Tablo 4. Analiz sonuçların karşılaştırılması

\begin{tabular}{|c|c|c|c|}
\hline & $\begin{array}{c}\text { Sayısal Analiz } \\
\text { (Solidworks) }\end{array}$ & $\begin{array}{c}\text { Sayısal Analiz } \\
\text { (Ansys) }\end{array}$ & $\begin{array}{c}\text { Deneysel Analiz } \\
\text { (Gerinim Ölçer ile) }\end{array}$ \\
\hline $\begin{array}{c}\text { Birinci Mod } \\
\text { Değeri }\end{array}$ & $5,67 \mathrm{~Hz}$ & $5,50 \mathrm{~Hz}$ & $5,75 \mathrm{~Hz}$ \\
\hline
\end{tabular}

Gerçek değere ne kadar yaklaşıldığının oransal bir gösterimi olan bağıl hata yöntemi Tablo 4'de kullanılacak olursa elde edilen değerler Tablo 5'deki gibi olmaktadır.

Tablo 5. Bağıl hata gösterimi

\begin{tabular}{|c|c|c|}
\hline & $\begin{array}{c}\text { Sayısal Analiz } \\
\text { (Solidworks) }\end{array}$ & $\begin{array}{c}\text { Sayısal Analiz } \\
\text { (Ansys) }\end{array}$ \\
\hline Bağıl Hata (\%) & 1,39 & 4,35 \\
\hline
\end{tabular}

Tablo 5'de verilen değerler (1) numaralı eşitlikteki formül kullanılarak hesaplanmıştır. Formülde gerçek değer olarak deneysel analiz sonucu, yaklaşık değerler olaraksa sayısal analiz sonuçları kullanılmıştır.

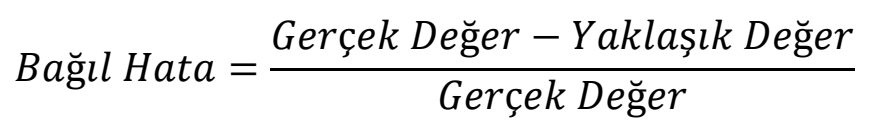




\section{Sonuç}

$\mathrm{Bu}$ çalışmada L tipi bir kirişin sayısal analiz programlarında sonlu elemanlar yöntemi ile modal analizleri gerçekleştirilmiş ve elde edilen sonuçlar deneysel veriler ile karşılaştırılmıştır. Sayısal modal analizler Solidworks Simulation ve Ansys programları kullanılarak gerçekleştirilmiştir. Her iki programda da aynı sınır şartları ve malzeme kullanılmıştır. Sayısal modal analizlerden elde edilen sonuçların deneysel modal analizden elde edilen doğal frekans değerine göre sapma miktarı \%1,39 ile \%4,35 arasında olmaktadır. Bu sonuç bize nihai tasarımdan önce gerçekleştirilecek olan sayısal analizlerin deneysel verilere ne kadar yakın olduğunu göstermektedir. Nihai tasarımdan önce sayısal analiz programları ile yapılacak ön tasarımın, üretimde zaman ve maliyet etkenlerini azaltarak ciddi bir bütçe tasarrufu sağlayabileceği açıkça görülmektedir.

\section{Kaynaklar}

[1] Karaoğlu S, Çiçek., 2008, Dip Klapesinin Ansys İle Tasarım Optimizasyonu. Pamukkale Üniversitesi Mühendislik Bilimleri Dergisi, 14(2), 155-160.

[2] Can, İ., 2015, Palet Sisteminin Sonlu Elemanlar Metodu İle Mukavemet Analizinin Yapılması Ve Optimizasyonu (Doctoral dissertation, Fen Bilimleri Enstitüsü).

[3] Hızır, O. G., 2011, Askeri Gemilerde Helikopter Güvertesinin Yapısal Ağırlık Optimizasyonu (Doctoral dissertation, Fen Bilimleri Enstitüsü).

[4] Yavuzcan, H. G., Önder, M., Keçel, S., Akkurt, A., Korkmaz, M. S., 2015, Yatık Ağız Açma ve Kalibre Etme Makinasının Yapısal Analizi Ve Ağırlık Optimizasyonu. Gazi Üniversitesi Fen Bilimleri Dergisi Part C: Tasarım ve Teknoloji, 3(3), 555-564.

[5] Kıral Z. Mekanik Titreşimler Ders Notları. http://kisi.deu.edu.tr/zeki.kiral/Mekanik _Titresimler_Ders_Notları_Zeki_Kiral.pdf

[6] Orhan S, Arslan H, Aktürk N. Titreşim Analiziyle Rulman Arızalarının Belirlenmesi. Gazi Üniversitesi Mühendislik-Mimarlık Fakültesi Dergisi, 2003, 18.2.

[7] Eldek, S. , Yılmaz, R. , Gülbahçe, E.. (2019). Bir Ucu Ankastre L Kirişin Strain Gauge ile Serbest Sönümlü Titreşim Analizi. Academic Perspective Procedia, 2 (3), 768-775. DOI: 10.33793/acperpro.02.03.84

[8] Metals Handbook, Howard E. Boyer and Timothy L. Gall, Eds., American Society for Metals, Materials Park, OH, 1985. 